\title{
Early Diastolic Dysfunction in Breast Cancer Patients Undergoing Chemotherapy
}

\section{Disfunção Diastólica Precoce em Pacientes com Câncer de Mama Submetidas à Quimioterapia}

Geanne Maria Holanda de Menezes Barroso ${ }^{1}$, Paulo Victor de Jesus Silva², Júlio César Oliveira Costa Teles ${ }^{2}$, Vinícius Antônio Santos Aragão ${ }^{2}$, Karin Yasmin Santos Fonsêcá $\mathbb{\mathbb { D }}^{2}$, Marília Marques Aquino $^{2}$, Ullany Maria Lima Amorim Coelho de Albuquerque ${ }^{2}$, Enaldo Vieira de $\mathrm{Mel}^{2}$, Antônio Carlos Sobral Sousa ${ }^{2}$, Joselina Luzia Menezes Oliveira²

${ }^{1}$ Department of Cardiology, University Hospital, Federal University of Sergipe, São Cristóvão, SE; ${ }^{2}$ Department of Medicine, Federal University of Sergipe, São Cristóvão, SE, Brazil

\begin{abstract}
Background: Chemotherapy for breast cancer is associated with serious cardiovascular complications such as heart failure. The left ventricular ejection fraction is the main parameter used to assess systolic function in these patients. However, the occurrence of diastolic dysfunction may precede that of systolic dysfunction.

Objectives: To evaluate left ventricle diastolic and systolic functions in women with breast cancer undergoing chemotherapy using anthracyclines.

Methods: This observational, longitudinal, analytical, and prospective study included 62 women with breast cancer aged 2175 years old who underwent echocardiography at baseline and after three months of treatment. Diastolic function parameters were evaluated, and the patients were classified as diastolic dysfunction type 1, 2, or 3. Systolic dysfunction was defined as a left ventricular ejection fraction $\leq 53 \%$.

Results: After three months of treatment, 35 patients (56.4\%) had type 1 diastolic dysfunction, while one (1.6\%) had type 2. Diastolic dysfunction was identified in 26 patients at baseline and developed in 10 patients during treatment. Diastolic function parameters, E wave velocity, and E/A ratio decreased significantly $(p<0.05)$ with chemotherapy; however, the others showed no significant variations. Only three patients had systolic dysfunction, but there was a greater reduction in left ventricular ejection fraction in the group that developed diastolic dysfunction during treatment versus the group with diastolic dysfunction at baseline $(p=0.04)$.
\end{abstract}

Conclusion: Diastolic dysfunction occurs early in women with breast cancer undergoing chemotherapy. Its onset during the course of treatment is associated with a significantly reduced left ventricular ejection fraction.

Keywords: Breast neoplasms; Cardiotoxicity; Echocardiography; Ventricular dysfunction.

\section{Resumo}

Fundamento: A quimioterapia para o câncer de mama está associada a complicações cardiovasculares graves, como a insuficiência cardíaca. A fração de ejeção do ventrículo esquerdo é o principal parâmetro para avaliar a função sistólica nessas pacientes. Todavia, a ocorrência de disfunção diastólica pode preceder à disfunção sistólica.

Objetivos: Avaliar as funções diastólica e sistólica do ventrículo esquerdo de portadoras de câncer de mama em tratamento quimioterápico com antraciclinas.

Métodos: Trata-se de estudo observacional, longitudinal, analítico e prospectivo. Estudaram-se 62 mulheres com câncer de mama, com idades de 21 a 75 anos, que realizaram ecocardiogramas basais e após 3 meses de tratamento. Avaliaram-se parâmetros de função diastólica, e as pacientes foram classificadas em disfunção diastólica tipos:1, 2 ou 3. Definiu-se a disfunção sistólica como fração de ejeção do ventrículo esquerdo $\leq 53 \%$.

Resultados: Decorridos 3 meses de tratamento, 35 pacientes (56,4\%) apresentavam disfunção diastólica tipo 1, e apenas uma (1,6\%) do tipo 2.

Mailing Address: Paulo Victor de Jesus Silva •

E-mail: paulo.victorjss@gmail.com

Manuscript received 5/10/2021; revised 8/2/2021; accepted 9/10/2021

DOI: $10.47593 / 2675-312 X / 20213404$ eabc215 
A disfunção diastólica ocorreu em 26 pacientes já na etapa basal e surgiu em dez indivíduos no decurso do tratamento. Os parâmetros de função diastólica velocidade de onda E e relação E/A diminuíram significativamente $(p<0,05)$ com a quimioterapia, todavia, os demais não tiveram variação significativa. Apenas três pacientes apresentaram disfunção sistólica, porém verificou-se maior redução da fração de ejeção do ventrículo esquerdo no grupo que desenvolveu disfunção diastólica durante o tratamento comparativamente ao grupo que apresentava já disfunção diastólica no período basal $(p=0,04)$.

Conclusão: A disfunção diastólica ocorre precocemente em portadoras de câncer de mama submetidas à quimioterapia. O surgimento de disfunção diastólica no decurso do tratamento se associa à redução significativa da fração de ejeção do ventrículo esquerdo.

Descritores: Cardiotoxicidade; Disfunção ventricular; Neoplasias da mama; Ecocardiografia

\section{Introduction}

Cancer is considered one of the greatest public health problems worldwide, and breast cancer has remained the most prevalent cancer in women for three decades. ${ }^{1}$ Most chemotherapy agents are cardiotoxic, with heart failure (HF) being the most common complication. ${ }^{2}$ In fact, mortality rates reach $60 \%$ among patients who develop HF during cancer treatment. ${ }^{2}$

Despite being cardiotoxic, anthracyclines continue to play an important role in the treatment of solid tumors such as breast cancers and lymphomas. ${ }^{3}$ Proposed mechanisms for anthracycline-mediated cardiotoxicity include increased oxidative stress via redox cycling of the quinone moiety of anthracyclines and through the formation of iron-anthracycline complexes; disruption of mitochondrial and cellular calcium homeostasis; disruption of mitochondrial energetics; deep radiation of ultrastructural proteins including tinin and dystrophin; direct DNA damage via the inhibition of 2-beta topoisomerase; the inhibition of survival pathways such as neuregulin 1 and Erb B2; and direct cytotoxic effects on cardiac progenitor cells, decreasing repair potential after myocardial injury. How exactly these mechanisms interact and lead to cardiac toxicity remains unknown. ${ }^{4}$

The frequency of cardiotoxicity in the population varies among established definitions and tools. The most widely accepted definition by cardiology and cancer communities is a reduction in left ventricular ejection fraction (LVEF) of more than ten percentage points in relation to the baseline value ${ }^{5}$ to a value lower than $53 \%{ }^{6}$ This definition is used as the standard in this study. The assessment of LV diastolic function is an important part of echocardiographic assessment since echocardiographic measurements of diastolic dysfunction (DD) are associated with an increased risk of HF and mortality in the general population ${ }^{7}$ and considered fundamental to the HF pathophysiology. ${ }^{8}$ Isolated DD itself is associated with an increased risk of morbidity and mortality. ${ }^{9}$

The prevention and early detection of cardiotoxicity are paramount in the management of cancer patients ${ }^{10}$ since the paradigm shift occurred from cancer as a final disease to a chronic cardiovascular disease condition among survivors after therapy.

Thus, this study aimed to evaluate the LV diastolic and systolic function of women with breast cancer undergoing chemotherapy with anthracyclines.

\section{Methods}

\section{Study population}

This observational, longitudinal, and prospective study included 62 women with breast cancer aged $>18$ years who were consecutively selected between November 2016 and July 2018 to reduce sampling bias. The clinical variables evaluated included age in years; anthropometric measurements (weight in kilograms and height in meters); body surface in square meters; vital signs (heart rate [HR], systolic blood pressure [SBP], diastolic blood pressure [DBP]); comorbidities (systemic arterial hypertension [SAH], diabetes mellitus, and dyslipidemia); smoking; family history of coronary artery disease (CAD); and medications used in chemotherapy.

All patients signed an informed consent form, and the Human Ethics Research Committee of the University Hospital of the Federal University of Sergipe and the boards of the participating institutions approved the study.

The study population underwent two echocardiographic tests: the first before the start of chemotherapy and the second three months later.

All patients used anthracyclines according to one of the two chemotherapy regimens defined by the attending oncologist: ACT, which included doxorubicin $\left(60 \mathrm{mg} / \mathrm{m}^{2}\right)$ and cyclophosphamide $\left(600 \mathrm{mg} / \mathrm{m}^{2}\right)$ administered in four cycles every 21 days followed by paclitaxel $\left(80 \mathrm{mg} / \mathrm{m}^{2}\right)$ in 12 cycles once a week for adjuvant and neoadjuvant treatment; and FEC, which included fluorouracil $\left(600 \mathrm{mg} / \mathrm{m}^{2}\right)$, epirubicin $\left(90 \mathrm{mg} / \mathrm{m}^{2}\right)$, and cyclophosphamide $\left(600 \mathrm{mg} / \mathrm{m}^{2}\right)$ administered in four cycles every 21 days, followed by docetaxel $\left(75 \mathrm{mg} / \mathrm{m}^{2}\right)$ in four cycles every 21 days.

No patient exceeded the maximum recommended anthracycline dose of doxorubicin $\left(240 \mathrm{~m} / \mathrm{m}^{2}\right)$ or epirubicin $\left(360 \mathrm{mg} / \mathrm{mg}^{2}\right) .{ }^{11}$ In addition, no patient underwent associated radiotherapy before the three-month evaluation.

Patients who attended the two echocardiography assessments during the study period were included. The exclusion criteria were previous structural heart disease, inadequate acoustic window, and previous chemotherapy or radiotherapy.

\section{Procedures}

All patients were examined using a Philips Epiq 7 ultrasound device with an X5-1 transducer and installed Automated Cardiac Motion Quantification (ACMQ; ) software. The same ultrasound device was used to obtain all echocardiograms for each patient. Sector and depth were adjusted to acquire an ideal view of the entire LV myocardium at the highest possible frame rate. The acquisition was obtained at the end of expiration. Multiple cardiac cycles from apical longitudinal three-chamber view (AP3L), four-chamber view (AP4L), and 
two-chamber view (AP2L) were acquired and recorded for subsequent analysis.

LVEF was calculated using the biplane disk method or Simpson's method with the ACMQ software from the AP3L, $\mathrm{AP} 4 \mathrm{~L}$, and $\mathrm{AP} 2 \mathrm{~L}$ acquisitions with automatic border detection and subsequently corrected manually. The ventricle was divided into a series of equal-height disks. The volume of each disk was calculated as the area multiplied by the height, and the sum of all disk volumes determined the ventricular volume. An LVEF > 53\% was considered normal. ${ }^{6}$

The following parameters were used to calculate the LV diastolic function: mitral diastolic flow with evaluation of $E$ and A wave velocities and E/A ratio with pulsed Doppler; and e' velocities with the tissue Doppler sample positioned in the septal and lateral rings. The mean E/e' ratio was calculated (normal values: septal $\mathrm{e}^{\prime}>7 \mathrm{~cm} / \mathrm{s}$, lateral $\mathrm{e}^{\prime}>10 \mathrm{~cm} / \mathrm{s}$, and mean E/ $\left.\mathrm{e}^{\prime}<14\right)$; left atrial volume index calculated with acquisition of $A P 4 L$ and $A P 2 L$ views starting before the opening of the mitral valve, calculated using the disk method, subsequently indexed by body surface, with the normal value established as $<34 \mathrm{~mL} / \mathrm{m}^{2}$; and tricuspid valve regurgitation velocity, whose normal value determined as the cutoff point was $<2.8 \mathrm{~cm} / \mathrm{s}$.

LV diastolic function was classified as normal if more than half of the variables were within normal limits and below the cutoff points. In addition, DD was identified if more than half of the parameters met the cutoff points. The study would be inconclusive if half of the parameters met their cutoff points and the other half of the parameters were normal. In patients with a preserved or reduced LVEF, when $\mathrm{E}$ wave velocity is $\leq$ $50 \mathrm{~cm} / \mathrm{s}$ and $\mathrm{E} / \mathrm{A}$ ratio is $\leq 0.8$, and the left atrial (LA) pressure is normal or low, then DD is classified as type 1 . When the $\mathrm{E} / \mathrm{A}$ ratio is $>2$ and $\mathrm{LA}$ pressure is high, the $\mathrm{DD}$ is defined as type 3 . When the $E$ wave velocity is $>50 \mathrm{~cm} / \mathrm{s}$ and the $E / A$ ratio $\leq 0.8$ (or $>0.8$ but $<2$ ), it is necessary to consider other parameters, such as tricuspid regurgitation (TR) peak velocity with continuous Doppler, E/e' ratio, and LA volume. The abnormality cutoff points are TR peak velocity $>2.8 \mathrm{~cm} / \mathrm{s}, \mathrm{E} / \mathrm{e}^{\prime}$ ratio $>14$, and indexed $L A$ volume $>34 \mathrm{~mL} / \mathrm{m}^{2}$. When two of these three parameters meet their cutoff points and the mean LA pressure is high, the DD is classified as type 2. Conversely, if two of these three parameters do not meet the cutoff points, the DD is classified as type $1 .{ }^{12}$ For comparative purposes, the sample was divided into three groups: Group 1, patients with DD at baseline; Group 2, patients who developed DD during the three months of treatment; and Group 3, patients who presented no DD at the three-month observation.

All tests were performed by a single examiner, the calculations were repeated, and the mean values of all measurements were analyzed.

\section{Statistical analysis}

Qualitative variables are expressed as frequency (percentage), while quantitative variables were subjected to the Shapiro-Wilk test to determine the distribution type. Those that fulfilled the assumption of normality are presented as mean and standard deviation. Non-normally distributed variables are described as median and interquartile ranges or maximum and minimum values.
The chi-square or Fisher's exact test was used to compare qualitative variables as appropriate. Student's t-test was used to compare the two main groups when continuous or discrete variables were normally distributed. Analysis of variance was used to compare patients among groups.

\section{Results}

Of the 63 patients eligible for the study, a satisfactory acoustic window for obtaining echocardiographic parameters was not achieved in only one. Thus, 62 patients were evaluated. The mean age of the 21 participants was 48.98 \pm 11.3 years (range, $46.11-51.85$ years). The clinical and epidemiological characteristics of the study population are shown in Table 1.

Most of the patients (36 [58.1\%]) presented with DD at the three-month evaluation. However, 26 patients (41.9\%; 95\% confidence interval [CI], 29-54.8\%) had DD at baseline that persisted at the three-month evaluation, $10(16.1 \%$; $95 \% \mathrm{Cl}$, 8.15-25.8\%) did not have DD at baseline but developed it by the three-month evaluation; and the remaining 26 patients (41.9\%; 95\% Cl, 29-54.8\%) did not present with DD at baseline or the three-month evaluation. As for DD type, only one patient had type 2, while the others had type 1 .

Of the risk factors, the population that presented with some DD at the three-month evaluation was older. In addition, the most prevalent risk factors of the population were $\mathrm{SAH}$, dyslipidemia, family history of CAD, and obesity, which were present in $33.9 \%, 32.3 \%, 12.9 \%$, and $8.1 \%$ of patients, respectively. There was a significant difference between $\mathrm{SAH}$ and non-SAH patients and dyslipidemic versus nondyslipidemic patients who presented with DD. The differences in obesity and family history of CAD among groups were insignificant. Data regarding risk factors and their statistical significance by group are shown in Table 2. No intergroup differences in symptoms were observed (Table 3).

The analysis of diastolic function parameters showed intergroup differences in mean variation of the $E$ wave velocity and the E/A ratio, which significantly decreased by three months after treatment. The lateral $\mathrm{e}^{\prime}$ parameter also showed significant intergroup variation during the study period and reductions in Groups 2 and 3. The other parameters did not differ significantly, and the mean values of the parameters, their variation after three months, and their respective statistical

Table 1 - General clinical characteristics of the sample.

\begin{tabular}{lc}
\hline Clinical characteristics & Total $(\mathbf{n}=\mathbf{6 2})$ \\
\hline Age, years & $48.98 \pm 11.30$ \\
Obesity & $5(8.1)$ \\
SAH & $21(33.9)$ \\
Diabetes & $3(4.8)$ \\
Dyslipidemia & $20(32.3)$ \\
Family history of CAD & $8(12.9)$ \\
Smoking & $3(4.8)$ \\
Hormone replacement & $5(8.1)$ \\
\hline
\end{tabular}

Results are expressed as mean \pm standard deviation or $n(\%)$. CAD: coronary artery disease; $\mathrm{SAH}$ : systemic arterial hypertension. 
significance are shown in Table 4. Furthermore, there was no significant intergroup difference in $\mathrm{HR}$ at the time of the echocardiographic assessment at three months after treatment. However, SBP and DBP differed significantly (Table 5).

95\% Cl: 95\% confidence interval; DBP: diastolic blood pressure; HR: heart rate; SBP: systolic blood pressure

Only three patients had systolic dysfunction according to the biplane method after three months of treatment. However, LVEF showed a greater mean decrease in the group that

Table 2 - Prevalence of risk factors by study group.

\begin{tabular}{lcccc}
\hline Risk factor & $\begin{array}{c}\text { Diastolic } \\
\text { dysfunction } \\
\text { at baseline } \\
(\mathrm{n}=\mathbf{2 6})\end{array}$ & $\begin{array}{c}\text { Diastolic } \\
\text { dysfunction } \\
\text { at 3-month } \\
\text { evaluation }(\mathrm{n}=10)\end{array}$ & $\begin{array}{c}\text { No diastolic } \\
\text { dysfunction } \\
\text { at 3-month } \\
\text { evaluation }(\mathrm{n}=26)\end{array}$ & P value \\
\hline Age, years & $57.30 \pm 8.28$ & $50.90 \pm 6.78$ & $39.92 \pm 8.23$ & 0.858 \\
Obesity & $3(11.5)$ & $1(10)$ & $1(3.8)$ & 0.576 \\
SAH & $12(46.2)$ & $5(50)$ & $4(15.4)$ & $0.03^{*}$ \\
Diabetes & $3(11.5)$ & 0 & 0 & 0.203 \\
Dyslipidemia & $14(53.8)$ & $2(20.0)$ & $4(15.4)$ & $0.01^{*}$ \\
Family history & $6(23.1)$ & $1(10.0 \%)$ & $1(3.8)$ & 0.107 \\
of CAD & $1(3.8)$ & $1(10)$ & $1(3.8)$ & 0.708 \\
Smoking & \multicolumn{4}{c}{ Results are expressed as mean \pm standard deviation or $n(\%) .{ }^{*}$ Statistically } \\
\hline significant. CAD: coronary artery disease; SAH: systemic arterial hypertension.
\end{tabular}

Table 3 - Signs and symptoms by study group.

\begin{tabular}{lcccc}
$\begin{array}{c}\text { Sign or } \\
\text { symptom }\end{array}$ & $\begin{array}{c}\text { Diastolic } \\
\text { dysfunction } \\
\text { at baseline } \\
(\mathrm{n}=26)\end{array}$ & $\begin{array}{c}\text { Diastolic } \\
\text { dysfunction } \\
\text { at 3-month } \\
\text { evaluation }(\mathrm{n}=10)\end{array}$ & $\begin{array}{c}\text { No diastolic } \\
\text { dysfunction } \\
\text { at 3-month }\end{array}$ & P value \\
Dyspnea & $5(19.2)$ & $1(10)$ & $1(3.8)$ & 0.213 \\
evaluation $(\mathrm{n}=26)$ & $1(3.8)$ & 0.091 \\
Palpitations & $2(7.7)$ & $3(30)$ & $2(7.7)$ & 0.124 \\
Precordial pain & $1(3.8)$ & $1(10.0)$ & $1(3.8)$ & 0.708 \\
Asthenia & $5(19.2)$ & $3(30.0)$ & $2(7.7)$ & 0.226 \\
Asymptomatic & $16(61.5)$ & $7(70.0)$ & $22(84.6)$ & 0.172 \\
\hline
\end{tabular}

Results are expressed as $n(\%)$. developed DD during treatment than in the group with DD at baseline $(p=0.041)$; however, there was no significant intergroup difference at the three-month evaluation $(p=$ 0.255) (Tables 6 and 7).

\section{Discussion}

The analysis of LV diastolic and systolic function is an essential part of the echocardiographic assessment, especially in cancer patients undergoing breast cancer treatment, as the observation of early echocardiographic changes is important for monitoring and starting cardioprotective medications. The current study presented important findings about early echocardiographic changes. First, there was a significant number of patients in whom DD developed during chemotherapy treatment; of them, 10 (16.1\%) developed DD after three months of treatment. Timothy et al..$^{15}$ reported a $20 \%$ rate of DD similar to that the present study; however, this was after a longer follow-up (12 months of echocardiographic evaluation). Furthermore, this early incidence of DD corroborates the literature since it is known that $\mathrm{LV}$ relaxation changes can be detected after one week of anthracycline use..$^{13}$ One of the main pathophysiological mechanisms of DD in the general population may be associated with cardiac oxidative stress, ${ }^{14}$ especially in the population being treated for breast cancer with anthracyclines, which are correlated with increased cardiac oxidative stress that can result in mitochondrial dysfunction, apoptosis, and necrosis. ${ }^{15}$

As for LV systolic function, after three months of treatment, only three patients $(4.8 \%)$ had systolic dysfunction according to the biplane method, while 10 developed DD after the three months of treatment, which suggests that LV DD presents earlier than LV systolic dysfunction. A longer follow-up period will be necessary to establish the clinical outcomes of these patients, but DD abnormalities over time are associated with subsequent systolic dysfunction and cardiotoxicity. ${ }^{7}$ It was also possible to observe that patients with baseline DD are less associated with reduced LVEF than those who develop DD throughout treatment, suggesting that baseline DD is not associated with subsequent systolic dysfunction, similarly to what Timóteo et al. ${ }^{16}$ and Upshaw et al. ${ }^{7}$ reported when following patients for 12 months and 6.5 years, respectively.

Table 4 - Mean, standard deviation, and statistical significance of diastolic dysfunction at baseline and the three-month examination.

\begin{tabular}{|c|c|c|c|c|c|c|c|}
\hline & \multicolumn{2}{|c|}{ Group 1} & \multicolumn{2}{|c|}{ Group 2} & \multicolumn{2}{|c|}{ Group 3} & \multirow{2}{*}{ P value* } \\
\hline & Baseline & 3 months & Baseline & 3 months & Baseline & 3 months & \\
\hline E wave velocity & $69.67 \pm 19.56$ & $65.45 \pm 13.02$ & $86.36 \pm 12.76$ & $61.17 \pm 14.94$ & $93.76 \pm 14.83$ & $88.17 \pm 13.37$ & $0.001 \dagger$ \\
\hline A wave velocity & $89.44 \pm 22.50$ & $89.77 \pm 17.9$ & $67.14 \pm 17.62$ & $79.48 \pm 16.27$ & $59.63 \pm 14.1$ & $62.71 \pm 13.17$ & 0.147 \\
\hline E/A ratio & $0.81 \pm 0.32$ & $0.76 \pm 0.28$ & $1.34 \pm 0.36$ & $0.78 \pm 0.08$ & $1.55 \pm 0.31$ & $1.48 \pm 0.27$ & $0.0002 \dagger$ \\
\hline Indexed left atrial volume & $25.93 \pm 6.71$ & $26.55 \pm 6.31$ & $23.73 \pm 4.83$ & $23.19 \pm 4.76$ & $29.21 \pm 29.89$ & $23.14 \pm 5.25$ & 0.514 \\
\hline E/e' ratio & $9.21 \pm 2.65$ & $8.63 \pm 2.15$ & $8.75 \pm 1.91$ & $7.38 \pm 1.36$ & $8.63 \pm 1.41$ & $8.62 \pm 2.02$ & 0.14 \\
\hline Septal e' & $6.35 \pm 2.11$ & $6.21 \pm 2.03$ & $7.75 \pm 1.70$ & $6.30 \pm 1.45$ & $8.86 \pm 2.08$ & $8.51 \pm 1.92$ & 0.224 \\
\hline Lateral e' & $9.08 \pm 3.22$ & $9.61 \pm 3.24$ & $12.35 \pm 1.81$ & $10.47 \pm 2.87$ & $13.69 \pm 2.69$ & $12.75 \pm 2.76$ & $0.035 \dagger$ \\
\hline
\end{tabular}

*Statistical significance of the mean variation after three months (analysis of variance). $†$ The tricuspid regurgitation velocity parameter is not in the table because it was not calculated in all patients since its use is only necessary when the other parameters are insufficient for classification. 
Table 5 - Mean heart rate and systolic and diastolic blood pressures of the groups on the echocardiographic assessment after three months of treatment with respective $p$ and confidence intervals.

\begin{tabular}{|c|c|c|c|c|c|c|c|}
\hline & \multicolumn{2}{|c|}{ Group 1} & \multicolumn{2}{|c|}{ Group 2} & \multicolumn{2}{|c|}{ Group 3} & \multirow{2}{*}{$P$ value } \\
\hline & Mean & $95 \% \mathrm{Cl}$ & Mean & $95 \% \mathrm{Cl}$ & Mean & $95 \% \mathrm{Cl}$ & \\
\hline $\mathrm{HR}$ & $86.04 \pm 13.92$ & $80.42-91.66$ & $91.30 \pm 14.21$ & 81.13-101.47 & $81.69 \pm 15.01$ & $75.63 \pm 87.75$ & 0.191 \\
\hline SBP & $142.01 \pm 20.80$ & $133.67-150.47$ & $133.90 \pm 14.69$ & $123.39-144.41$ & $123.16 \pm 19.01$ & $115.47-130.83$ & $0.003^{*}$ \\
\hline DBP & $77.65 \pm 8.89$ & $74.06-81.24$ & $77.30 \pm 11.11$ & $69.36-85.24$ & $70.65 \pm 10.05$ & $66.60-74.71$ & $0.028^{*}$ \\
\hline
\end{tabular}

*Statistically significant. 95\% Cl: 95\% confidence interval; DBP: diastolic blood pressure; HR: heart rate; SBP: systolic blood pressure.

Table 6 - Mean reduction and standard deviation of the biplane ejection fraction after three months in Groups 1 and 2.

\begin{tabular}{lccc}
\hline & Group 1 & Group 2 & P value \\
\hline $\begin{array}{l}\text { Mean reduction and standard } \\
\text { deviation in BPEF after three months }\end{array}$ & $0.59 \pm 10.1$ & $8.21 \pm 8.31$ & 0.041 \\
\hline
\end{tabular}

BPEF: biplane ejection fraction.
Table 7 - Mean reduction and standard in biplane ejection fraction after three months in Groups 2 and 3.

\begin{tabular}{lccc}
\hline & Group 1 & Group 2 & P value \\
\hline $\begin{array}{l}\text { Mean reduction and standard } \\
\text { deviation in BPEF after three months }\end{array}$ & $8.21 \pm 8.31$ & $4.62 \pm 8.23$ & 0.255 \\
\hline FEBP: fração de ejeção pelo método biplanar. & & \\
\hline
\end{tabular}

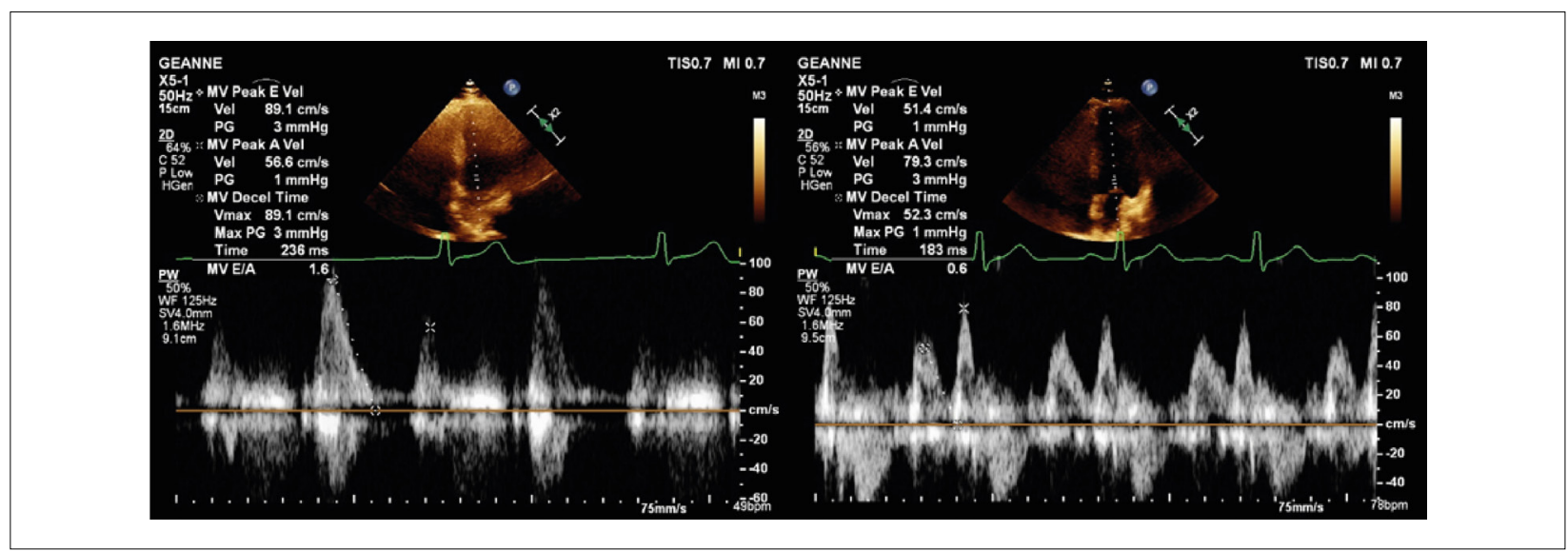

Figure 1 - Evaluation of a patient's $E$ wave, $A$ wave, and E/A ratio during the study. (A) Basic parameters: $E$ wave velocity of $89.1 \mathrm{~cm} / \mathrm{s}, A$ wave velocity of $56.6 \mathrm{~cm} / \mathrm{s}$, E/A ratio of 1.6. (B) Parameters after three months of chemotherapy: $E$ wave velocity of $51.4 \mathrm{~cm} / \mathrm{s}, A$ wave velocity of $79.3 \mathrm{~cm} / \mathrm{s}$, and E/A ratio of 0.6 . Note the decreased $E$ wave and E/A ratio after three months of treatment.

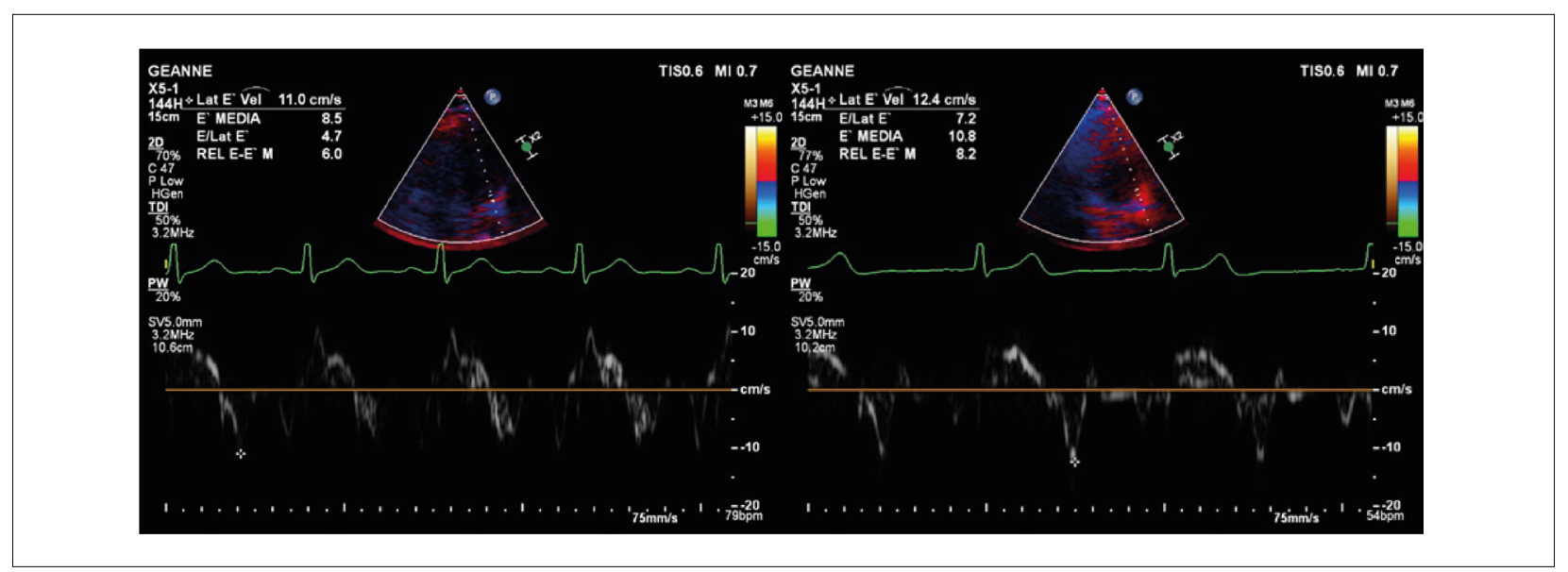

Figure 2 - Razão E/e' de uma paciente durante o estudo. (A) E/e' de 6,0 basal. (B) E/e'de 8,2 da mesma paciente após 3 meses de tratamento. Ambos os valores dentro do limite da normalidade. 
Other important findings were related to diastolic function parameters. A significantly reduced $\mathrm{E}$ wave velocity and $\mathrm{E} / \mathrm{A}$ ratio were noted early on, while $\mathrm{AE}$ and $\mathrm{E} / \mathrm{e}^{\prime}$ indexed volume parameters showed no significant variation. Similar changes in mitral inflow (reduced E/A ratio) were reported in other studies, such as those by Serrano et al. ${ }^{17}$ and Ho et al., ${ }^{18}$ the latter also reporting a significantly reduced $\mathrm{E}$ wave velocity. Despite being an important tool to assess remodeling and, indirectly, LA function, the indexed LA volume has low sensitivity in the early stages. ${ }^{19}$ In turn, variations in the $\mathrm{E} / \mathrm{e}^{\prime}$ parameter are also linked to chronic conditions, ${ }^{13,20}$ which justifies the absence of changes in both parameters in the present study. Timóteo et al. ${ }^{16}$ showed significant indexed LA volume changes, but not until later - on 12-month echocardiography follow-up.

Factors such as HR and systemic blood pressure should be considered in the context of assessing diastolic function. ${ }^{12}$ The present investigation showed no significantly different intergroup mean HR, suggesting that the observed changes in mitral inflow were not directly impacted by this parameter. On the other hand, SBP and DBP differed among the three groups, with higher mean echocardiographic evaluation values in Groups 1 and 2 after treatment due to the greater number of chronic hypertensive patients within them.

One of the limitations of the study was the evaluation time, which, despite having demonstrated early echocardiographic changes in the studied population, did not allow the objective assessment of the long-term behaviors of the systolic and diastolic function parameters correlated with the occurrence of cardiovascular outcomes. It would also be interesting to evaluate the behavior of diastolic and systolic parameters in patients undergoing additional chemotherapy treatment with trastuzumab after anthracycline since the patients did not undergo the former due to the short evaluation time. Another important limitation stems from the dependence of mitral inflow parameters on hemodynamic conditions, such as volume depletion, a side effect related to chemotherapy

\section{References}

1. Siegel RL, Miller KD, Jemal A. Cancer statistics, 2018. CA Cancer J Clin. 2018;68(1):7-30. doi: 10.3322/caac. 21442

2. Thavendiranathan P, Poulin F, Lim KD, Plana JC, Woo A, Marwick TH. Use of myocardial strain imaging by echocardiography for the early detection of cardiotoxicity in patients during and after cancer chemotherapy: a systematic review. J Am Coll Cardiol. 2014;63(25 Pt A):2751-68. doi: 10.1016/j.jacc.2014.01.073.

3. Smith LA, Cornelius VR, Plummer CJ, Levitt G, Verrill M, Canney P, Jones A. Cardiotoxicity of anthracycline agents for the treatment of cancer: systematic review and meta-analysis of randomised controlled trials. BMC Cancer. 2010;10:337. doi: 10.1186/1471-2407-10-337

4. Kimmick G, Dent S, Klem I. Risk of Cardiomyopathy in Breast Cancer: How Can We Attenuate the Risk of Heart Failure from Anthracyclines and Anti-HER2 Therapies? Curr Treat Options Cardiovasc Med. 2019 May 31;21(6):30. doi: 10.1007/s11936-019-0736-1

5. Cardinale D, Colombo A, Bacchiani G, Tedeschi I, Meroni CA, Veglia F, Civelli M, Lamantia G, Colombo N, Curigliano G, Fiorentini C, Cipolla CM. Early detection of anthracycline cardiotoxicity and improvement with heart failure therapy. Circulation. 2015;131(22):1981-8. doi: 10.1161/ CIRCULATIONAHA.114.013777

6. Plana JC, Galderisi M, Barac A, Ewer MS, Ky B, Scherrer-Crosbie M, et al. that does not allow the conclusion that the $\mathrm{E}$ wave and $\mathrm{E} / \mathrm{A}$ ratio changes observed result directly from its cardiotoxicity. However, it is known that the situations mentioned here are inherent to the study population and methodology.

\section{Conclusion}

The study data demonstrated that DD occurs early in breast cancer patients undergoing chemotherapy and that its development during treatment is associated with a significant LVEF reduction compared to patients with DD at baseline. The significantly changed early diastolic function parameters include a reduced E wave velocity, lateral $\mathrm{e}^{\prime}$, and E/A ratio. Further longer-term follow-up studies are needed to assess intergroup differences in cardiovascular outcomes and identify which myocardial function parameters would be chronically changed.

\section{Acknowledgments}

The authors thank the patients and family members who supported the research during therapy as well as the professionals involved who encourage and strengthen research in the state of Sergipe.

\section{Authors' contributions}

Research conception and design: Barroso GMHM; manuscript writing: Barroso GMHM; data analysis and interpretation: Silva PVJ; data collection: Aragão VAS, Fonsêca KYS, Aquino MM, and Albuquerque UMLAC; statistical analysis: Melo EV and Silva PVJ; critical review of the manuscript for important intellectual content: Sousa ACS and Oliveira JLM.

\section{Conflict of interest}

The authors have declared that they have no conflict of interest.

Expert consensus for multimodality imaging evaluation of adult patients during and after cancer therapy: a report from the American Society of Echocardiography and the European Association of Cardiovascular Imaging. Eur Heart J Cardiovasc Imaging. 2014;15(10):1063-93. doi: 10.1093/ehjci/jeu192

7. Upshaw JN, Finkelman B, Hubbard RA, Smith AM, Narayan HK, Arndt $\mathrm{L}$, et al. Comprehensive assessment of changes in left ventricular diastolic function with contemporary breast cancer therapy. JACC Cardiovasc Imaging. 2020;13(1 Pt 2):198-210. doi: 10.1016/j. jcmg.2019.07.018

8. Faris R, Coats AJ, Henein MY. Echocardiography-derived variables predict outcome in patients with nonischemic dilated cardiomyopathy with or without a restrictive filling pattern. Am Heart J. 2002;144(2):343-50. doi: 10.1067/mhj.2002.123844

9. Redfield MM, Jacobsen SJ, Burnett JC Jr, Mahoney DW, Bailey KR, Rodeheffer RJ. Burden of systolic and diastolic ventricular dysfunction in the community: appreciating the scope of the heart failure epidemic. JAMA. 2003;289(2):194-202. doi: 10.1001/jama.289.2.194

10. Zamorano JL, Lancellotti P, Rodriguez Muñoz D, Aboyans V, Asteggiano R, Galderisi M, et al.; ESC Scientific Document Group. 2016 ESC Position Paper on cancer treatments and cardiovascular toxicity developed under 
the auspices of the ESC Committee for Practice Guidelines: The Task Force for cancer treatments and cardiovascular toxicity of the European Society of Cardiology (ESC). Eur Heart J. 2016;37(36):2768-801. doi: 10.1093/ eurheartj/ehw211

11. Armenian SH, Lacchetti C, Barac A, Carver J, Constine LS, Denduluri N, et al. Prevention and Monitoring of Cardiac Dysfunction in Survivors of Adult Cancers: American Society of Clinical Oncology Clinical Practice Guideline. J Clin Oncol. 2017;35(8):893-911. doi: 10.1200/JCO.2016.70.5400

12. Nagueh SF, Smiseth OA, Appleton CP, Byrd BF 3rd, Dokainish H, Edvardsen $\mathrm{T}$, et al. Recommendations for the evaluation of left ventricular diastolic function by echocardiography: an update from the American Society of Echocardiography and the European Association of Cardiovascular Imaging. J Am Soc Echocardiogr. 2016;29(4):277-314. doi: 10.1016/j. echo.2016.01.011

13. Stoodley PW, Richards DA, Boyd A, Hui R, Harnett PR, Meikle SR, et al. Altered left ventricular longitudinal diastolic function correlates with reduced systolic function immediately after anthracycline chemotherapy. Eur Heart j Cardiovasc Imaging. 2013;14(3):228-34. doi: 10.1093/ehjci/jes139.

14. Jeong EM, Dudley SC Jr. Diastolic dysfunction. Circ J. 2015;79(3):470-7. doi: 10.1253/circj.CJ-15-0064

15. Zuppinger C, Timolati F, Suter TM. Pathophysiology and diagnosis of cancer drug induced cardiomyopathy. Cardiovasc Toxicol. 2007;7(2):61-6. doi: 10.1007/s12012-007-0016-2

16. Timóteo AT, Moura Branco L, Filipe F, Galrinho A, Rio P, Portugal $\mathrm{G}$, et al. Cardiotoxicity in breast cancer treatment: What about left ventricular diastolic function and left atrial function? Echocardiography. 2019;36(10):1806-13. doi: 10.1111/echo.14487

17. Serrano JM, González I, Del Castillo S, Muñiz J, Morales LJ, Moreno F, et al. Diastolic Dysfunction Following Anthracycline-Based Chemotherapy in Breast Cancer Patients: Incidence and Predictors. Oncologist. 2015;20(8):864-72. doi: 10.1634/theoncologist.2014-0500

18. Ho E, Brown A, Barrett P, Morgan RB, King G, Kennedy MJ, et al. Subclinical anthracycline-and trastuzumab-induced cardiotoxicity in the long-term followup of asymptomatic breast cancer survivors: a speckle tracking echocardiographic study. Heart. 2010;96(9):701-7. doi: 10.1136/hrt.2009.173997

19. Pathan F, D'Elia N, Nolan MT, Marwick TH, Negishi K. Normal ranges of left atrial strain by speckle-tracking echocardiography: a systematic review and meta-analysis. J Am Soc Echocardiogr. 2017;30(1):59-70.e8. doi 10.1016/j.echo.2016.09.007

20. Mesquita ET, Jorge AJ. Entendendo a disfunção diastólica assintomática na prática clínica. Arq Bras Cardiol. 2013;100(1):94-101. doi: https://doi. org/10.1590/S0066-782X2013000100015. 